\title{
Overview of Cloud-based Learning Management System
}

\author{
Hassan Faisal Aldheleai \\ Department of Computer \\ Science, \\ Aligarh Muslim University, \\ Aligarh, India
}

\author{
Mohammad Ubaidullah \\ Bokhari \\ Department of Computer \\ Science, \\ Aligarh Muslim University, \\ Aligarh, India
}

\author{
Abdulsalam Alammari \\ School of Computer and \\ Information Sciences \\ University of Hyderabad
}

\begin{abstract}
Using cloud computing as a new inspiration for creative learning environment gives the learner new space to go beyond, the hardware and software challenges. Cloud computing comes with fully equipped levels of services, to facilitate the different needs of a single learner or group of learners to big organization, giving each one a free hand to design their own training program according to their subjects and requirements. Moreover this study is reviewing the usability of cloud technology for third world countries like Yemen

In this paper we are trying to give brief interdiction to cloud computing and cloud-based LMS, with some examples of some fumes platforms using this technology, moreover we tried to summarize the main advantages and drawback of using this technology to serve learner on the era of online learning.
\end{abstract}

\section{Keywords}

Cloud, Cloud-computing, E-learning, Learning Management System, LMS, Education. Yemen,

\section{INTRODUCTION}

When you connect any of your devices to the power outlet in the wall, you don't care how did you got this energy or where it was generated, and what plant size by breeding this electricity, and how it was stored and distributed till it reached your socket on the wall. All the previous process is a virtual for you, you're only concerned that your device has worked and has to perform the desired function. Once again think about it, if computing is considered to work totally virtualize, processing to be done in one place another place for storing data, and as well resources of the software will be provided from different places, simply this is possible with cloud computing, where everything is available as services [1].

Techniques such as cluster, grid, and at the moment the cloud computing technology, all designed to allow Login and view the largest possible computing information and whatever services offered for user in completely virtualize way, by assembling, connecting and inventory of these processes and to present it in a single device. In another way it can be viewed as computing utility.

Introducing the idea of the cloud basically came run-down of the change made in the method of dealing with the computer and problems using it [2].
With all these changes in using computer, and the way of providing services, all these come to serve the growth of elearning. Elearing-based cloud environment ensures targeted users smooth computing environment and software services. In elearing-based cloud universe, learners can avail access to virtual services whenever they need it wherever they are.

With different layers of cloud computing, elearning can use the base layer of cloud computing to allow millions of learners use IT facilities resources, sharing the same infrastructure. The layer of hardware performs the way similar to the Internet, where it allows sharing of hardware assets securely and in capable way. Finally with the platform layer, which take the responsibility of all activities of storing mass data, business intelligence operations and many operations, which have been difficult to be performed, The interface or what we call it LMS (Learning Management System) provides the ability of course management to schools, colleges and universities [3] [4].

\section{CLOUD TECHNOLOGY}

The idea of connecting users to the services like storing, retrieving and manipulating the data via the Internet are called cloud computing, for instance a user can solve an acquisition or manipulate data using high performance system available only via the Internet, some of these services are free to use, and some other may draw some cost to user, it is still optional as many services are offered to be paid as much as consumer need to use. Cloud computing is a powerful utility offered to users having the Internet connection, this utility is divided into three layers [5] [6].

\subsection{Structure of cloud comporting}

Cloud computing is built up on three layers as we can see in the fig 1 , as explained in the previous the structure of layers as services show the main idea of cloud computing stricture.

1. Infrastructure as a service (IaaS) provide the hardware as a service

2. Platform as a service (PaaS) a powerful layer provide user with all means of both hardware and software compound as services, enabling developer to create and execute application.

3. Software as a service (SaaS) provide software as a service [7].

With different services being offered users have the right to select from the services available in LMS platform. They may pick one or even many different services according to their requirement to achieve one or more tasks. Desktop, laptops smartphones and other devices may connect to the Internet, also software like cloud based applications or website 
operating in a browser all these devices can act as client in the cloud computing [8][9] .

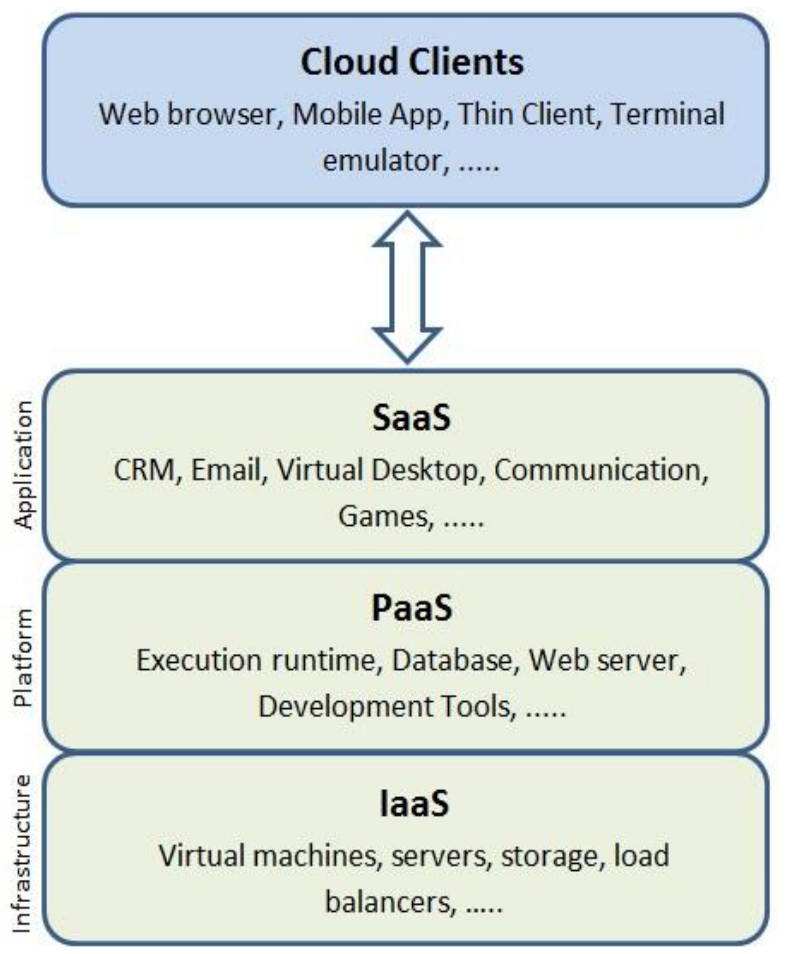

Fig 1: Layers of cloud computing

Fig 2 shows the services offered in each layer comparing with the services offered in traditional IT (Information Technology), we can see the huge difference between traditional IT, where user have to manage all the services locally, with could computing technology services user are free of doing all this tasks as everything is offered as services [8].
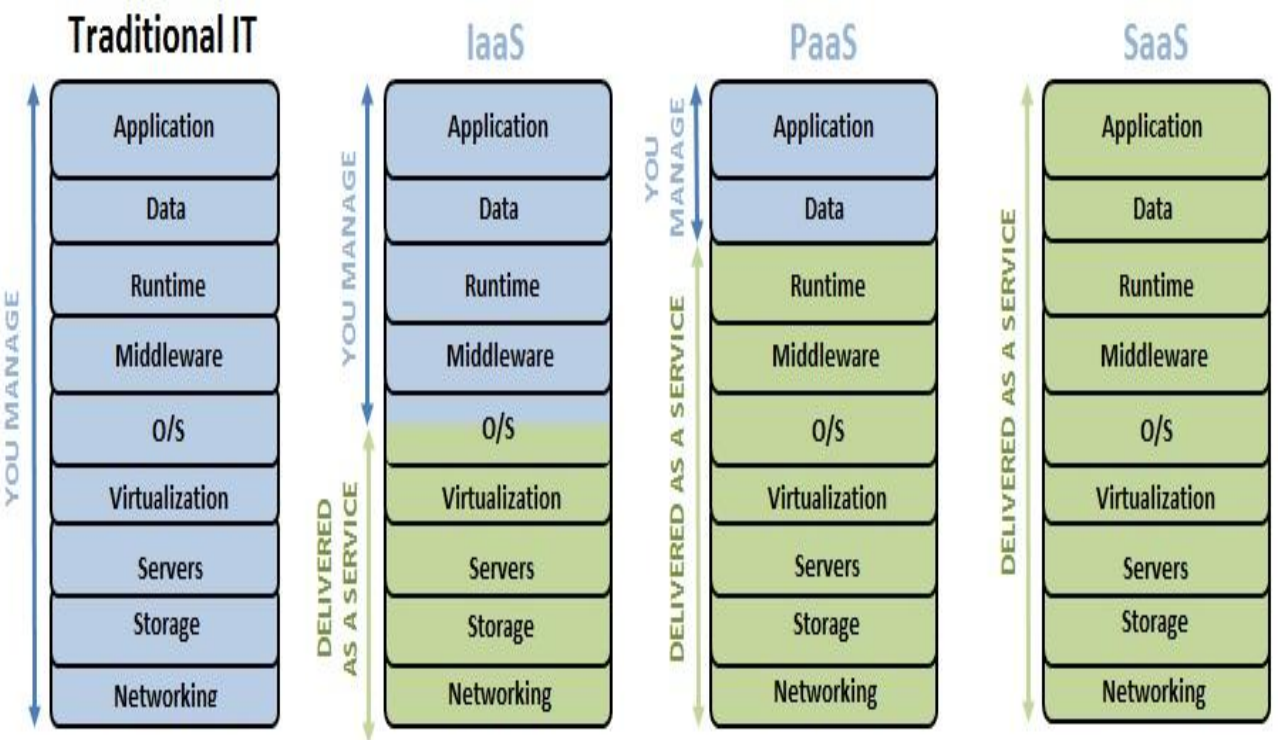

Fig 2: The services offered in each layer of the cloud computing compering with Traditional IT.

In fig 3 we see the deployment of three types of the cloud computing where learners can connect directly to both public and hybrid clouds. But in case of getting connection to private clouds more authentication process will be required to login to the private servers and start viewing and manipulating the

\subsection{Cloud Computing Deployment Types}

Cloud computing spreads over the Internet is divided into three types which are private, public and hybrid cloud:

\subsubsection{Public Cloud}

This type of cloud is available in the Internet for anyone desired to use the services offered, it offers a very high speed bandwidth to be able to handle a large number of public user, thousands of services are available most of these services are free of cost. Public clouds are very good for handling small enterprise task [3].

\subsubsection{Private Clouds}

Unlike the public cloud, private cloud have limited space and users, usually this type of cloud is widely used in private organizations (like companies and hospitals) to enable their own users accessing to IT services within the organizations, perhaps the organization have strong control on the cloud infrastructure [10]. With the limited number users allowed to login to this cloud, this make it more secure as must of information shared are confidential and need higher security like the company employees profiles and more different files related to company incomes and trading [3].

\subsubsection{Hybrid Clouds}

Hybrid clouds, is a cloud came up to cover the shared area between private clouds and public clouds, this area contains some information and processes which is basically within a private cloud of an organization but doesn't carry any confidential information, perhaps it can be shared within a public clouds for every user [3]. Thus, organizations still keep their significant information within their own private cloud by using their IT utility infrastructure available inside the organization; meanwhile they still can benefit of public cloud to auto-scale their assets. The hybrid cloud is applicable to services that are associated to IT technical facilities more than software services [10] [11]. 


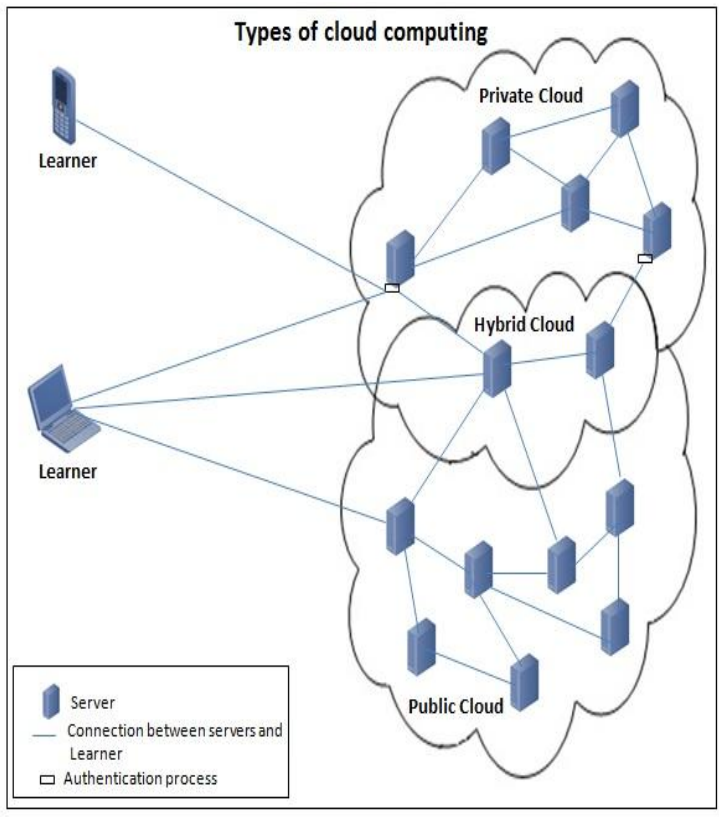

Fig 3: Cloud computing Deployment Types

Fig 4 shows the fast respond to adopt cloud computing and the repaid demand of cloud computing in different level of technology markets [12].

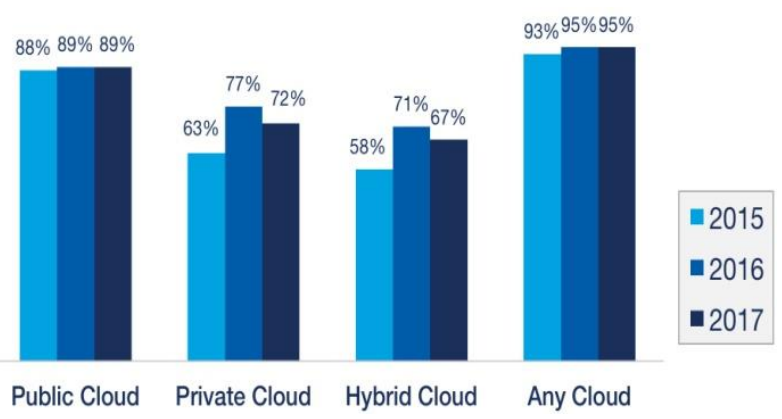

Fig 4: Respondents adopting Clouds in 2015 up to 2017

\section{LEARNING MANAGEMENT SYSTEM (LMS)}

The software which is managing the learning process that is created in different types of platforms, either can be used in traditional IT or cloud-based are called "Learning Management System" (LMS). Many types of LMS some are of used to keep and maintain learning process, like web portals that assemble different links in the web and offer them to a learner, it may also view video files library to assist learner achieve their search. Other LMS may offer some kind of online exams and analysis the whole level performance in order to get to higher stage or level, while many other LMS can offer the learner some special functions, this function may draw higher cost which mad it over budget for some learners [13].

\section{LMS BASED CLOUD}

The use of LMS in cloud created a huge development change in the way that user think about using the Internet as media for e-learning, and give more flexibility for a user to learn and interact with learning system, users can create their accounts and benefits of different services available. In this section some examples of famous LMS system platforms that use cloud computing are reviewed.

\section{EXAMPLES OF LMS WITH CLOUD}

Here we introduce some well-known LMS platforms based cloud computing, that provide wide verity of tools online to a learner.

\subsection{WizIQ.}

Is one of the biggest platforms offering LMS-based cloud in the global, WizIQ was first established in 2007. Today WizIQ have around four hundred thousands of tooters to design and deliver different teaching materials in one platform to over four millions of users spreads around two hundred countries worldwide [14].

With this LMs software user will be able to have actual experience of training that simulates the real time experience, this can be achieved using some fixable tools that aid user to design their own experiences like setup, ship and maintain their own training programs to reflect the user thinking and allowing learner to create their own environment [15].

\subsection{Docebo}

Docebo LMS known for it's easy to use front page with malty functions user can be in full control of the system. Docebo make it possible for companies to create their own platform as online learning brand, and it enable the learners to use the learning system as much as they pay for, using online trainer or apps in mobile [15]. Docebo is serving companies as well academic organization, with it you can have many models that gives multi options for learners to select from. Moreover Docebo has the ability to support external interface systems like video conference and CRM [16].

\subsection{Litmos}

Litmos is a cloud based learning management system, and it is situated in the SaaS layer of the cloud structure. Litmos was basically designed and is frequently used to deliver online train courses for organizations members, giving a platform for many academic organizations, health care, small enterprise business and government different departments. This LMS was first developed and introduced at Silicon Valley in San Francisco Bay Area of California, United States. Right now there are around four million subscribers in Litmos [17].

\subsection{TalentLMS}

TalentLMS is a SaaS eLearning platform, and it's very powerful platform to create your e-learning course, design the content, plan for test and do survey among your learners. All this can be achieved with many fixable tools and utilities provided to ease learner work and because of all this they call it course management system CMS [15]. This platform is frequently used by medium to small organization to train their members and keep them always updated. As this platform can be run in ios and android, it also give an option for a user to work offline which make it a good option for many learners. TalentLMS spreads for training purpose in many areas like health organization, public departments, retail sector and some other unprofitable organization may use it also for different purposes, this platform was first developed in 2011 and its first vibration was in market in 2012 [18].

In the fig 5 we can see the info-graphic ranking of the four platforms with reference to users reviews, integration, mobile application, media presence and security [19]. 


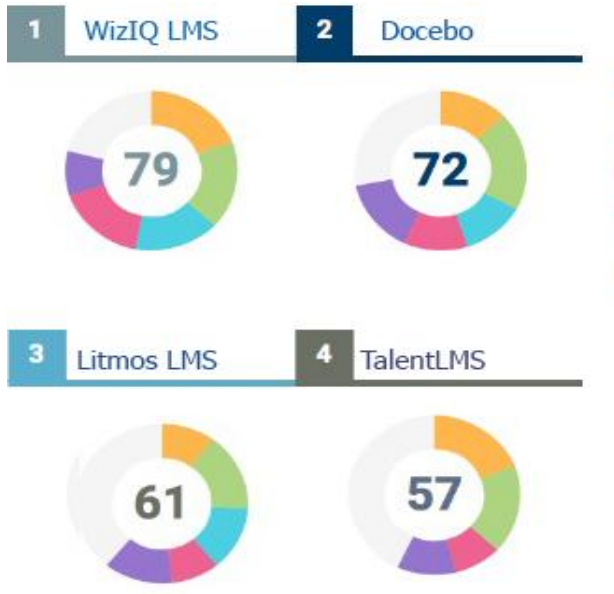

Fig 5: info-graphic ranking of the four Platforms.

\section{BENEFITS OF USING CLOUD- BASED LMS}

With cloud computing being used to support Learning Management System, learners are getting lots of benefits. in this section we will try to give brief notes about the main benefits of using LMS based cloud computing.

\subsection{Lower start-up cost}

With cloud computing user doesn't need to buy any software or go through the installation and upgrading process which normally software go through, moreover the maintenance [20]. With cloud all users need only to make sure about Internet connection no need to worry about software or hardware compatibility. Users have only to open browser in their devices and create their own accounts and start planning their work, the thing which is very interesting is that most LMS providers offer free trails for some pried of time and if you are satisfy with their services you can go ahead with subscription plans, some others providers offer free accounts but in case users need more storage space or more tools they have to pay for that services, This makes user save not only wallet but you save their time also, and stay away from the headache of software installation problems and debagging [21] [22].

\subsection{Enhanced data security}

Using different media to communicate and share ideas and information regarding company business, courses materials and designs in free social media like twitter and Facebook may expose this information for screening and theft from unwanted third party. In cloud based LMS things are more privets and secured, you can share all of your information securely in the organization own network. Moreover if required to do any payment some secure system are used like stripe to offer high security to users payments and their payment information like cards number and bank details [20].

\subsection{Improved accessibility}

Better accessibility for both learner and course developers, is reality with cloud based LMS which gives everybody a tangible ability to stay logged in their account anywhere using different type of devices. They have only to access their accounts from Smartphones, Tablets or Phablet or any other devices having the Internet connectivity to continue wherever they have stopped before regard less of the place or device [20][22].

\subsection{Faster deployment}

Using cloud based LMS to design course materials and content is very easy task, but the easer with cloud computing is deploying this course. In most of the cloud based LMS all what you have to do is just clicking the Publish butane, then you can see your learning course available worldwide, and learner can access to the materials from everywhere [20].

\subsection{Cost predictability}

Using cloud based LMS, make users in full control and more planed about their bill payments final cost, even monthly or for a long plans of one or two years, maybe more than that depends up on the packages offered and promotion being served along with each package [22] .

\subsection{Be up-to-date with technologies}

One of the best thing of using cloud based LMS that both course developers and learners will be up to date with latest technology, as the platform service provider will be responsible for updating the software and hardware technology to keep competitive in market and to gain more subscribers [22].

\subsection{More storage space}

It is very important feature of cloud based LMS, with this feature you don't have to be so much concerned about where to store your data and your local PC hard disc capacity, and it is better solution to stop carrying CD's, DVD's and external hard disc as it's very easy to log in to your data any time you need it, user have only to upload his data in cloud servers. Storage space available in cloud not only save your money and time but also save your data from being lost or damaged, which frequently happened with local storage unites in normal devices, cloud offers users large storage capacity with no cap on the total storage and high maintenance, user also can Organize, reuse and share files with selected users., moreover some cloud platforms offers recovery option for the deleted data, like which make user more secure about their significant data [20].

\subsection{Fully customizable and scalable}

Most of cloud based LMS platforms gives ability to user to customize their page interface and course material design, test and survey. User also can control how the course will be delivered and how learners are going to go further in their learning process toward next level certificates [22].

\section{CHALLENGES OF USING CLOUD- BSED LMS}

While there is so many benefits of using cloud based LMS, we still have so many challenges, which really should be talked to maximize the benefits learner is getting from this type of online learning.

Here we mention some of the main challenges that learner may face while using the different LMS in the Internet.

\subsection{Risks related to data protection and security}

The cloud based LMS are implementing high technologies to protect user information, but still as long as this information available in the Internet it is vulnerable to different types of hacking attacks. This makes this personal information and organization significant data in high risk.

We can summarize the most important risks which affects cloud-computing, and the main related to the security in cloud 
as follow [7] [20].

- $\quad$ loss of governance

- $\quad$ lock-in

- $\quad$ isolation failure

- $\quad$ compliance risks

- management interface compromise

- data protection

- insecure or incomplete data deletion

- malicious insider

- protection of intellectual property and of the data in cloud

\subsection{Dissemination politics, intellectual property}

Some individual or organization may use some learning materials without having the copy right or possess the prober licensing for using and deploying such properties. And for having license to use information, this may draw extra charges to user.

\subsection{Speed/lack of Internet can affect work methods}

Cloud based LMS are successful in most of the cases to serve different organization and users for a different purpose, but in some countries the lack of internet infrastructure perhaps lack of internet speed and availability may affect the learning process and over all learning quality. In addition in such countries internet browsing is very costly, this make it quite difficult for individuals to subscribe to any LMS course over the Internet, especially in the third world countries, in which this type of learning (e-learning) is very important to support the classic learning in schools [20].

\subsection{Lack of Standards \& confidence}

One of the advantages of cloud-computing is the high availability, but when the internet is over loaded with wide range of courses from different companies, all are pretend to have the best LMS platform, At the same time most of them are happy to offer many tools and different utilities, at the end with this vast verity of LMS available over the Internet, there is no specific stander that make user confident when learners go ahead using any LMS platform. Perhaps this create some lack of trust in all these courses available in the Internet and create a negative thinking about the cloud based LMS and make user view it as west of money and time [23] [7].

\section{USABILITY FOR YEMEN ENVIRONMENT}

Yemen is one of the third world countries and one of the poorest countries in the world. Hence education system in the country cannot offer education for everybody, especially children under 18 years. This is due to the difficult geographical surface of Yemen in which most of high intensity of population are leaving in mountains, that attract high cost of infrastructure of roads, hospital, schools and telecommunication systems,

We view cloud-based Learning management as one of the solution not only for Yemen, but for the most of the third world countries.
In Yemen still they are facing two important obstacles to establish any LMS specialized for Yemen. First one is lack of power supply in the whole country. The second thing is the lack of telecommunication to provide internet services especially in the rural and remote areas of mountains and deserts.

In the current time most of Yemen's are using solar panels to secure continues and uninterrupted power supply. However telecommunication will be the main problem of any LMS wanted to be implemented in Yemen.

\section{CONCLUSION}

The cloud computing is a huge development not only in the way of sharing information, but with its open space to give ability for sharing of hardware, software and platforms as services, which saves a lots of efforts of learners can't secure such utilities for their studies or daily use. And in particular it enable peoples leaves in under development countries to come over all this obstacles as soon as they get internet connections, which will be much easier in the near future with the raped improvement in telecommunication.

Still privacy issue is there and one of the main problems related to clouds, we have to worry and be so careful while using cloud computing and cloud based LMS. personal information is very sensitive and crucial in counties like Yemen, where cloud based LMS will be much beneficial for female learners, but when it comes to personal information any threat to such data will make many learner to think many times before subscribing to any cloud based LMS. This is a critical factor for female learners acceptance of such facility in counties such Yemen.

\section{REFERENCES}

[1] R. Buyya, J. Broberg, and A. Goscinski, Cloud Computing: Principles and Paradigms. 2011.

[2] J. D. Prince and J. D. Prince, "Introduction to Cloud Computing Introduction to Cloud Computing," vol. 4065, no. April, pp. 3-42, 2016

[3] R. (Department of C. S. \& E. G. H. Baniwal, "Applications of Cloud Computing in Different Areas," IJCSC, vol. 4, no. 2 September 2013, pp. 174-176 ISSN-0973-7391, 2013.

[4] P. Bientinesi, R. Iakymchuk, and J. Napper, Handbook of Cloud Computing. 2010

[5] M. Creeger, "CTO Roundtable: Cloud Computing," Commun. ACM, vol. 52, no. 8, pp. 50-56, 2009.

[6] S. P. Mirashe and N. V Kalyankar, "Cloud Computing," Commun. ACM, vol. 51, no. 7, p. 9, 2010.

[7] S. Vitkar, "Cloud Based Model for E-learning in Higher Education," Int. J. Adv. Eng. Technol., vol. 3, no. 4, pp. 38-42, 2012.

[8] A. S. Weber, "Cloud Computing in Education," Ubiquitous Mob. Learn. Digit. Age, pp. 19-36, 2013.

[9] A. Fernández, D. Peralta, F. Herrera, and J. M. Benítez, "An overview of e-learning in cloud computing," Adv. Intell. Syst. Comput., vol. 173 AISC, pp. 35-46, 2012.

[10] S. K. Garg and R. Buyya, "Garg 2011 - Green Cloud computing and Environmental Sustainability."

[11] N. Radhakrishnan, N. Poorna Chelvan, and D. Ramkumar, "Utilization of cloud computing in E- 
learning systems," Proc. 2012 Int. Conf. Cloud Comput. Technol. Appl. Manag. ICCCTAM 2012, no. February, pp. 208-213, 2012.

[12] B. Meteorology, "RightScale 2017 STATE OF THE CLOUD REPORT," 2017.

[13] T. Kaewkiriya and N. Utakrit, "A Model of an eLearning Management System Based on Cloud Computing and Web Service," vol. 8, no. 1, pp. 83-87, 2012.

[14] "WizIQ - Wikipedia." [Online]. Available: https://en.wikipedia.org/wiki/WizIQ. [Accessed: 08-Mar2017].

[15] "Top 10 Cloud Based Learning Management Systems For Corporate Training - eLearning Industry." [Online]. Available: https://elearningindustry.com/top-10-cloudbased-learning-management-systems-for-corporatetraining. [Accessed: 09-Feb-2017].

[16] "Open Source LMS - 10 Alternatives to Moodle | Barry Sampson." [Online]. Available: http://barrysampson.com/2009/04/08/open-source-lms10-alternatives-to-moodle/. [Accessed: 08-Mar-2017].

[17] "Litmos LMS «E-Learning 24/7 Blog." [Online]. Available: https://elearninfo247.com/productreviews/litmos-lms-top-5-pick/. [Accessed: 08-Mar-
2017].

[18] A. Papagelis and P. Zaharias, "Gamifying a Learning Management System: The case of TalentLMS," II Int. Work. Gamification Educ. gEducation 2015.

[19] "Infographic: The Top 25 Learning Management Systems - eLearning Brothers." [Online]. Available: http://elearningbrothers.com/infographic-top-25learning-management-systems/. [Accessed: 08-Mar2017].

[20] M. Miller, "Cloud Computing: Web-Based Applications That Change the Way You Work and Collaborate Online," Que Publ., pp. 1-29, 2009.

[21] F. Karim and I. I. R. Goodwin, "Using Cloud Computing in E-learning Systems," Int. J. Adv. Res. Comput. Sci. Technol., vol. 1, no. 1, pp. 65-69, 2013.

[22] D. Kaplanis, "8 Top Benefits of Using a Cloud Based LMS - eLearning Industry." [Online]. Available: https://elearningindustry.com/8-top-benefits-of-using-acloud-based-lms. [Accessed: 09-Mar-2017].

[23] E. A. Aldakheel, "A Cloud Computing Framework for Computer SciencelrlnEducation," no. December, 2011. 